\title{
Value systems and locus of control of people undergoing aesthetic surgery and their application in the work environment: a case study in Cyprus
}

L. Pantazi ${ }^{7}$ and H. Zavrides ${ }^{2}$

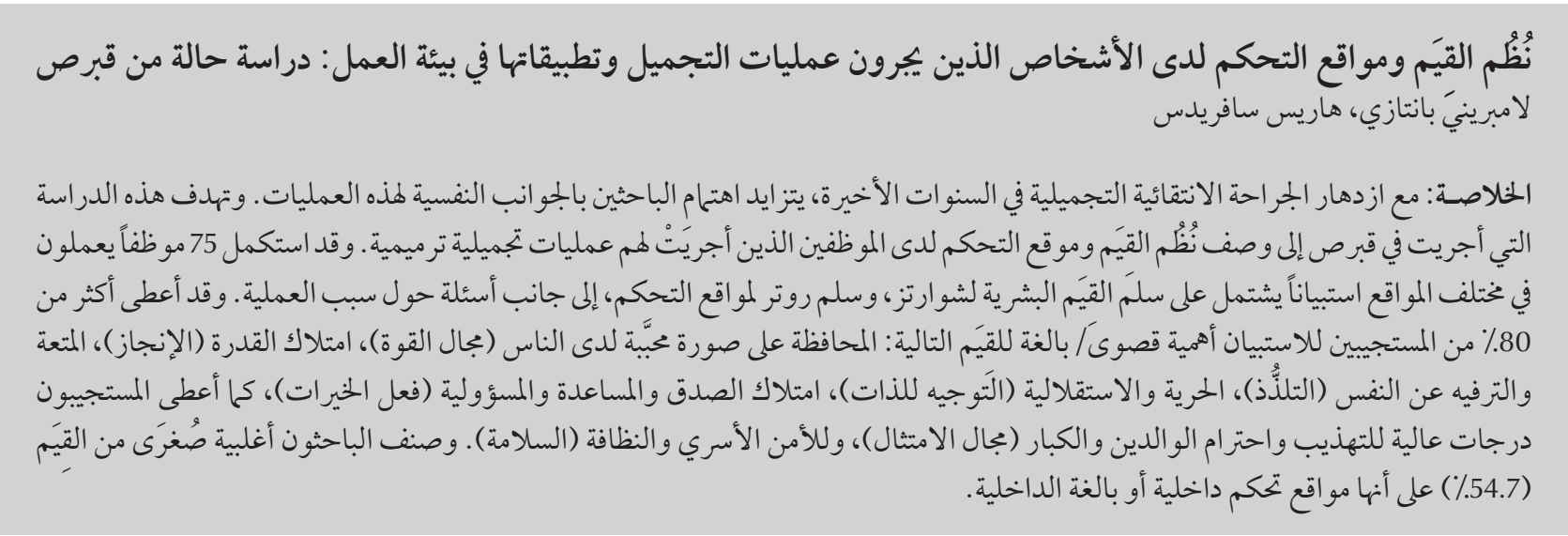

ABSTRACT With the growth in elective aesthetic plastic surgery in recent years researchers are becoming increasingly interested in the psychological aspects of the procedure. The aim of this research in Cyprus was to describe the value systems and the locus of control of employees who have undergone aesthetic plastic surgery. A questionnaire comprising the Schwartz human value scale, the Rotter scale for locus of control and questions about the reason for surgery was completed by 75 employees in a range of occupations. The values rated as very/ supremely important by $>80 \%$ of respondents were: preserving public image (power domain), being capable (achievement), pleasure and self-indulgence (hedonism), freedom and independence (self-direction) and being honest, helpful and responsible (benevolence). They also scored highly on politeness and honouring parents and elders (conformity domain) and family security and being clean (security). A small majority (54.7\%) was classified as internal or extreme internal locus of control.

Systèmes de valeurs et locus de contrôle des personnes ayant bénéficié d'une chirurgie esthétique et leur application dans le milieu professionnel : étude de cas à Chypre

RÉSUMÉ Avec l'augmentation de la chirurgie plastique esthétique programmée au cours des dernières années, les chercheurs se sont de plus en plus intéressés aux aspects psychologiques de l'intervention. Le présent travail de recherche mené à Chypre visait à décrire le système de valeurs et le locus de contrôle d'employés ayant bénéficié d'une chirurgie plastique esthétique. Un questionnaire comprenant l'échelle des valeurs universelles de Schwartz, l'échelle de Rotter pour les locus de contrôle et des questions sur les motifs de la chirurgie a été rempli par 75 employés exerçant des métiers variés. Les valeurs évaluées comme très/extrêmement importantes pour plus de 80 \% des répondants étaient les suivantes : préserver son image publique (pouvoir), être capable (réussite), se faire plaisir et s'accorder une gratification personnelle (hédonisme), aimer la liberté et l'indépendance (autonomie) et être honnête, secourable et responsable (bienveillance). Leurs résultats étaient aussi élevés dans les domaines de la politesse, du respect des parents et des anciens (conformité), de la sécurité familiale et de la propreté (sécurité). Une petite majorité $(54,7$ \%) avait un locus de contrôle interne ou un locus de contrôle interne extrême. 


\section{Introduction}

Value theory has been an important issue in cross-cultural psychology since Rokeach's work [1]. Most social scientists view values as deeply rooted, abstract motivations that guide, justify or explain attitudes, norms, opinions and actions. Description of the value systems of a specific population can lead us to targeted decisions and applications in the work environment. Schwartz developed a theory of potentially universal aspects in the content of human values [2-5] and in 2000 identified 10 distinct types of motivational values and explored the dynamic relations among them [6]. Another important theoretical concept affecting behaviour in the work environment is Rotter's theory of locus of control (LOC) [7]. A LOC orientation is a belief about whether the outcomes of our actions are dependent on what we do (internal) or on events outside our personal control (external). People that are classified as internal tend to be more achievement oriented and get better paid jobs. Research studies in the last decade regarding value systems or LOC are important because they give us information about how people react and behave in the work environment [8-11].

With the growth in elective aesthetic plastic surgery in recent years researchers are becoming increasingly interested in the psychological aspects of the procedure [12-14]. We have previously conducted a study regarding the self-esteem, self-image and self-confidence in the work environment of people who have undergone aesthetic plastic surgery [15]. The results showed that all these 3 variables scored higher after the operation. The purpose of this current research was to identify and describe the value systems and LOC of employees (in a range of occupations) who have undergone aesthetic plastic surgery and to interpret these results in relation to the work environment.

\section{Methods}

\section{Sample}

Our sample included 75 individuals (60 women and 15 men) aged 18 years or above who had undergone aesthetic plastic surgery and at that point in time were active in work or were students. The survey was administered to participants during their postoperative visits with a designated plastic surgeon and 30-40 days after the intervention. This period was judged sufficient for the individuals to be completely recovered from their operations so that they were able identify the results of the aesthetic plastic surgery and translate the new reality (perception of friends, colleagues and relatives of their new look).

\section{Measures}

In order to measure their variables, the authors developed a questionnaire that was a combination of the following: the Schwartz value survey [6]; the Rotter scale of locus of control [7]; and a series of questions that the authors developed regarding perceptions of the sample connected with the desire of the surgery, reasons for the surgery, work environment, etc. Essential information for the third part of the survey was determined through personal, pilot interviews. The questionnaire consisted of $92 \mathrm{ex}-$ ploratory questions and 7 demographic questions; 29 questions were the closed type ("a" or "b"), 61 questions had to be answered using a 9-point scale (Likert) ranging from -1 (opposed to my values) to 7 (supremely important), and 2 questions were multiple choices regarding the type of aesthetic procedure and the reason for the surgery.

\section{Data collection}

The questionnaire was completed by participants in the surgeon's plastic surgery department during one of the postoperative visits and during the interval already reported. Consent forms were distributed to all the participants and collected before their commitment.
The individuals were informed about the anonymity of the survey data. The patients completed the questionnaire in about 30-45 min. They were not given detailed instructions, but only general information concerning the purpose and the objectives of the research. The patients were encouraged to read carefully the first page of the questionnaire, which provided explicit and complete directions for its completion.

\section{Data analysis}

SPSS, version 16.0 was used for the data analysis. The analysis included descriptive statistics and cross-correlations of variables.

\section{Results}

\section{Background characteristics}

The age profile of the sample was $17.3 \%$ aged $18-25$ years, $28.0 \% 26-35$ years, $40.0 \% 36-45$ years, 9.3\% 46-55 years and $5.3 \% 56+$ years. In terms of profession, $20.0 \%$ worked in the private sector, $16.0 \%$ in education, $10.7 \%$ in law, $9.3 \%$ in the public sector, $9.3 \%$ entrepreneurship, $6.7 \%$ students, 5.3\% health, 5.3\% media and $17.3 \%$ other. Furthermore, $84.0 \%$ held a degree from college/university, whereas $6.7 \%$ had graduated from high school, $6.7 \%$ had graduated from middle school and only $2.6 \%$ had graduated from elementary school. Additionally, $5.3 \%$ earned $€ 0-1500,52.0 \%$ earned $€ 1501-3000$ and $42.7 \%$ earned $>€ 3001$ per month.

The types of operation were as follows: $30.7 \%$ rhinoplasty, $24.0 \%$ breast augmentation, $10.7 \%$ face lift, $8.0 \%$ otoplasty, $8.0 \%$ liposuction, $6.7 \%$ breast reduction, 5.3\% blepharoplasty, 5.3\% abdominoplasty and $1.3 \%$ mastopexy. The reported reasons for the operations were as follows: $74.7 \%$ for psychological reasons, $9.3 \%$ to feel more sexually desirable, $8.0 \%$ for occupational reasons, $5.3 \%$ because their sexual partner desired it and $2.7 \%$ due to their social environment. 


\section{Desire for aesthetic surgery and importance of self-image and occupation}

Table 1 shows the respondents' ratings for desire for aesthetic surgery, importance of self-image in the work environment and importance of occupation in their life. Desire for aesthetic surgery was rated supremely important by $41.3 \%$ of respondents. Importance of self-image in the work environment was rated lower (21.3\%), so too was importance of occupation in life (34.7\%). Statistically significant correlations were found between importance of occupation in life and desire for aesthetic plastic surgery $(t=0.342 ; P<0.001)$ and importance of self-image in work environment $(t=0.359 ; P<0.001)$. However, there was no statistically significant correlation between the variables desire for aesthetic plastic surgery and the importance of self-image in the work environment.

\section{Values system: descriptive statistics of individual values}

Table 2 shows the responses to the Schwartz value survey. The highest scoring item was preserving public image in the power domain (95\% rated it important or supremely important), while wealth was rated important/ supremely important by $75 \%$. In the achievement value the items capable and successful had high scores ( $86 \%$ and $76 \%$ ). For the self-direction value the items freedom (86\%) and independent (89\%) score highly but also choosing your own goals (79\%) and creativity (76\%). All the 5 items of the benevolence value were rated important/supremely important by high proportions of respondents, and the highest scoring items were being honest ( $81 \%)$, helpful (82\%) and responsible $(87 \%)$. For the hedonism value the items pleasure and self-indulgent were rated very/supremely important by $85 \%$ and $84 \%$ of respondents respectively. The conformity value had 2 high scoring items: politeness (85\%) and honouring parents and elders (90\%). For the security value there were also 2 items with high scores: family security (91\%) and being clean (82\%); national security was only rated important/supremely by $77 \%$ of respondents.

\section{Values systems: correlations}

The correlations between the items in each of the values domains showed that most items were correlated with 1 or more other items (Table 2).

In the power domain, significant statistical correlations were found between wealth and social power $(t=$ 0.374; $\mathrm{df}=73 ; P<0.001)$, between wealth and authority $(t=0.234 ; P<$ $0.001)$ and between social power and authority $(t=0.467 ; P<0.001)$. In the achievement domain significant correlations were found in most cases, specifically between ambitious and capable $(t=0.468 ; P<0.001)$, between ambitious and successful $(t=0.253$;
$P<0.005)$ and between capable and successful $(t=0.464 ; P<0.001)$. Regarding the items of the self-direction domain, choosing your own goals was significantly correlated with curious ( $t=$ 0.406; $P<0.001)$ and with creativity $(t=0.432 ; P<0.001)$, and the variable creativity showed a significant correlation with choosing your own goals $(t=$ $0.432 ; P<0.001)$ and with freedom $(t=$ $0.532 ; P<0.001)$

In the benevolence domain the item loyal had significant correlations with the items honest $(t=0.581 ; P<$ 0.001), helpful $(t=0.300 ; P<0.001)$, forgiving $(t=0.352 ; P<0.001)$ and responsible $(t=0.419 ; P<0.001)$, while the variable honest had a significant correlation with forgiving $(t=0.440 ; P$ $<0.001)$ and responsible $(t=0.402 ; P$ $<0.001$ ).

\section{Locus of control}

Regarding the LOC classification, a majority of the sample (54.7\%) was classified as internal to extreme internal (48.0\% of the sample were internal and $6.7 \%$ extreme internal) and $45.3 \%$ were external LOC.

\section{Discussion}

\section{Desire for aesthetic plastic surgery}

Unsurprisingly, desire for aesthetic surgery was rated supremely important by $41.3 \%$ and very important by $26.7 \%$ of this group who had undergone

\begin{tabular}{|c|c|c|c|c|c|c|c|}
\hline \multirow[t]{3}{*}{ Item } & \multirow{2}{*}{$\begin{array}{l}\text { Opposed to } \\
\text { my values } \\
\text { (score }-1)\end{array}$} & \multicolumn{4}{|c|}{ Important } & \multirow{2}{*}{$\begin{array}{c}\text { Very } \\
\text { important } \\
\text { (score 6) }\end{array}$} & \multirow{2}{*}{$\begin{array}{r}\text { Supremely } \\
\text { important } \\
\text { (score 7) }\end{array}$} \\
\hline & & (score 2) & (score 3 ) & (score 4) & (score 5) & & \\
\hline & $\%$ & $\%$ & $\%$ & $\%$ & $\%$ & $\%$ & $\%$ \\
\hline Desire for aesthetic surgery & 2.7 & - & 2.7 & 12.0 & 14.7 & 26.7 & 41.3 \\
\hline $\begin{array}{l}\text { Importance of self-image in the } \\
\text { work environment }\end{array}$ & - & 1.3 & 2.7 & 13.3 & 29.3 & 32.0 & 21.3 \\
\hline Importance of occupation in life & - & - & 1.3 & 9.3 & 14.7 & 40.0 & 34.7 \\
\hline
\end{tabular}

Based on scores on a 9-point Likert scale (-1 to 7). 


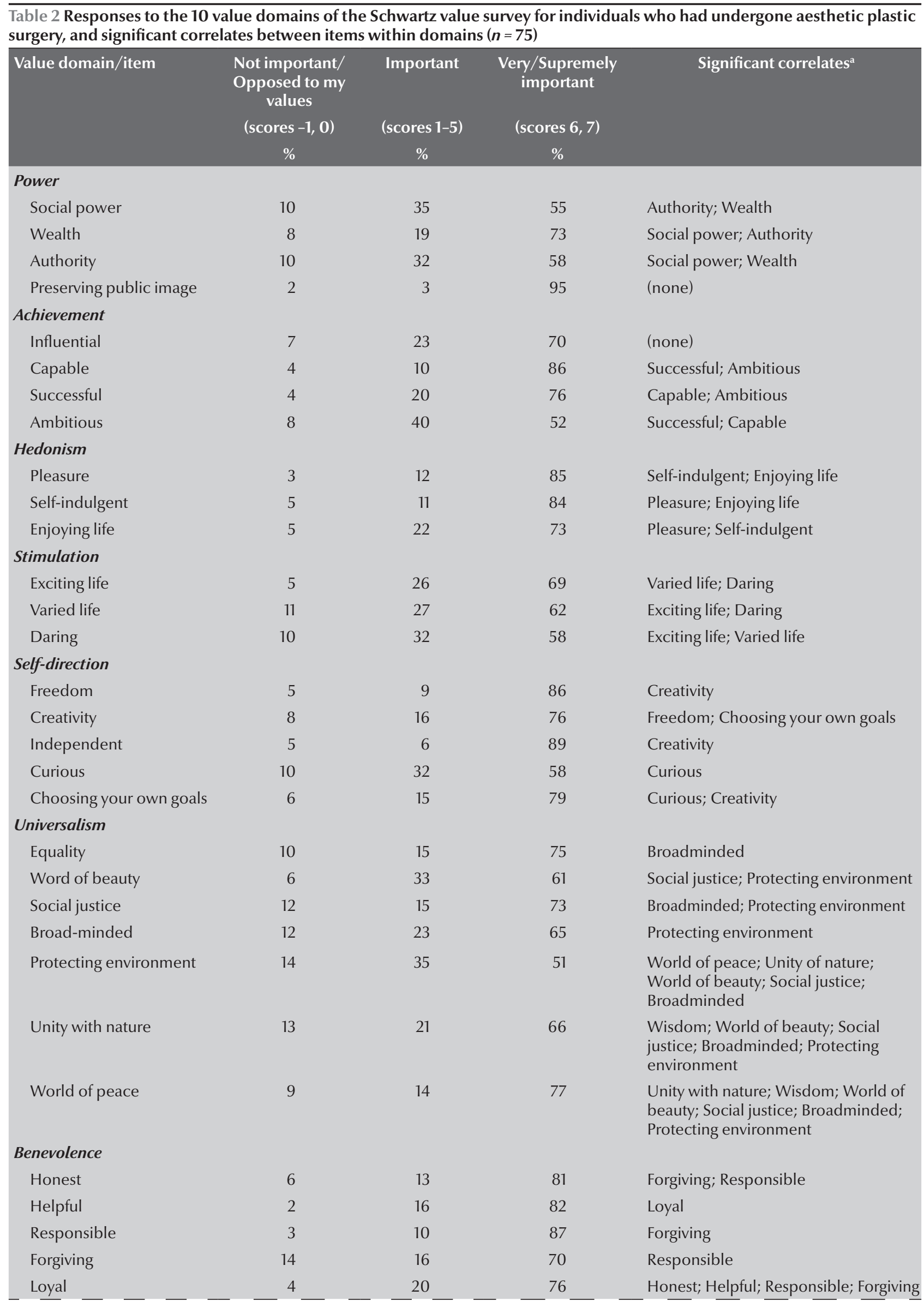




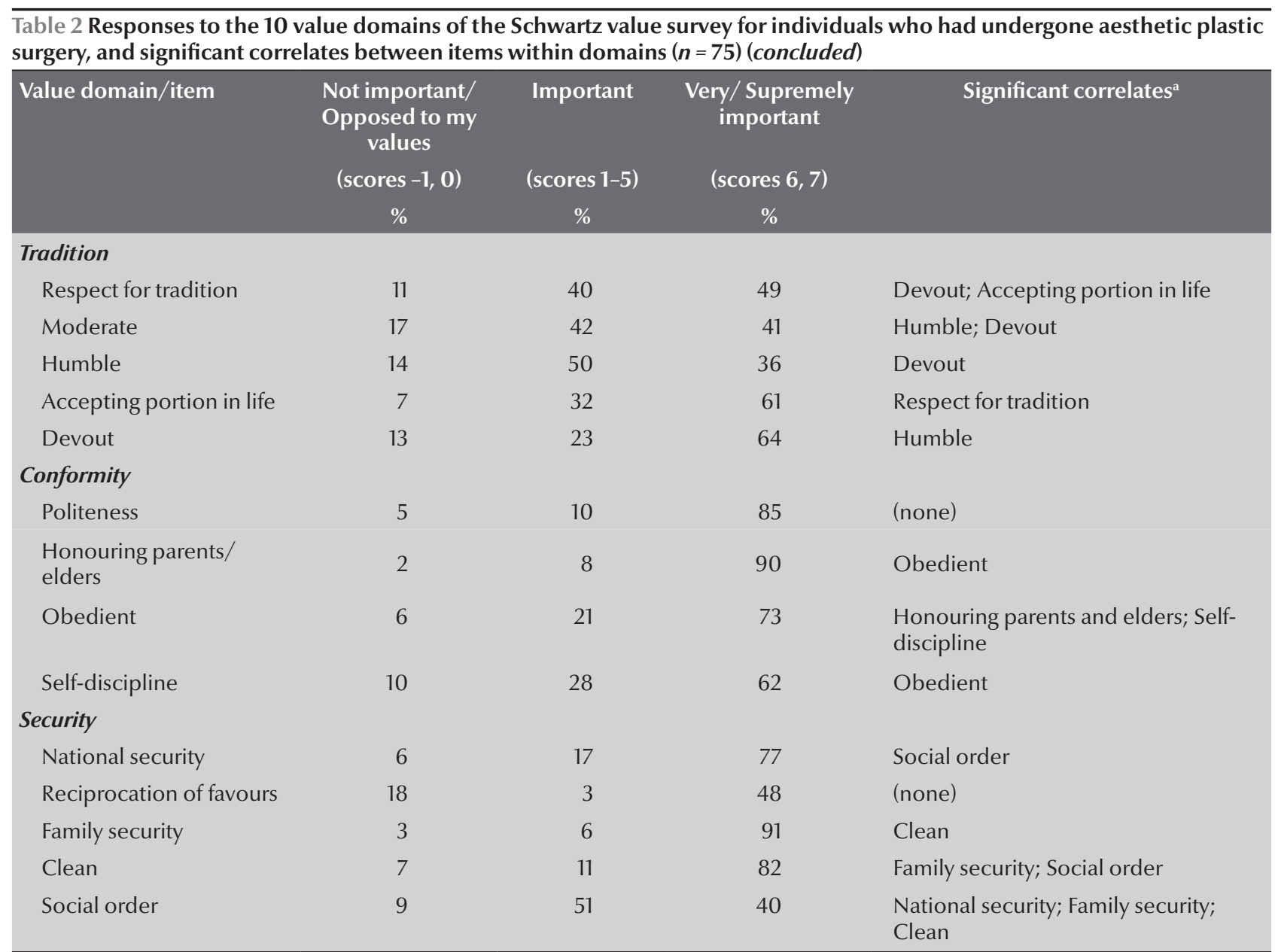

Based on scores on a 9-point Likert scale (-7 to 7). ${ }^{a} \mathrm{P}<0.001$ (t-test).

aesthetic plastic surgery. Desire for aesthetic surgery was correlated with importance of occupation in life but not with importance of self-image in the work environment. Importance of occupation to their life was statistically significantly correlated with importance of self-image in the work environment. Valuing their occupation highly and the importance of self-image at work offers some explanation of why they would be willing to proceed in an aesthetic plastic surgery in order to improve their appearance [16].

\section{Value systems}

Based on the analysis of value systems, the results led to the following interpretations. Regarding the value of power, it seems that the sample gave supreme importance to preserving public image (95\% rating this important/supremely important). This finding is consistent with the fact that individuals who have undergone aesthetic plastic surgery are likely to give high value to their appearance. Also, more than 55\%-73\% of the sample believed that wealth, social power and authority were very important for them. These 3 variables are important in perceptions regarding the work environment. For example, it is expected that people who desire wealth or authority are willing to work more in order to satisfy those desires [17]. Along with the descriptive statistics, the correlation analysis indicated consistency in the responses of the sample. Regarding the value of achievement, a value that is very important for the work environment, $70 \%-86 \%$ of the sample believed that being capable, successful and influential were very/supremely important for them. The variable ambitious was the only one that was rated very important by fewer of the respondents (52\%). There was a significant correlation among most of the variables. All the above results indicate that people that undergo aesthetic surgery are individuals that have characteristics that are highly appreciated in the business world [17]. For another important value, selfdirection, the analysis indicated that the sample valued freedom, creativity, independence and choosing their own goals. Characteristics such as creativity and independence are highly appreciated in the business world [18].

For the value of hedonism, the sample believed that enjoying life, pleasure and self-indulgent were variables of great importance. Once again, we found a statistically significant correlation among 
the variables; individuals seeking all the above will be satisfied and will bring this happiness (good mood) to their work environment as they do to their personal life [19]. Regarding the value of stimulation, the sample also believed that an exciting life, varied life and daring were very important factors for them, and the correlation analysis was significant. We can assume that these characteristics apply not only in their personal life, but in their work life too [20].

The value of universalism showed that most of the variables were scored as very/supremely important by between $51 \%-75 \%$ of the sample and there was a significant correlation among almost all the variables. However, the finding that only $77 \%$ answered that world of peace is very/extremely important was surprising, especially as Cyprus has faced challenges to peace since the Turkish invasion in 1974. Similarly, in the value of security, only $77 \%$ of the sample believed that national security was very/supremely important. We believe that these variables requires further research.

For the value of benevolence the sample believed that being honest, helpful, responsible and forgiving were very important to them. All these are characteristics are necessary in the business world, especially when a task requires group effort [21]. Based on the results regarding the value of tradition the results indicated that this group of people did not score high on values of tradition$\mathrm{al}$, moderate or humble. This is not surprising as these are characteristics that we would not expect to find in people who undergo aesthetic plastic surgery [22]. Regarding the value of conformity, the study found some interesting results. There was a significant correlation between politeness and honouring parents and elders and the sample seemed to favour obedience, since $73 \%$ believed that it was very/extremely important to be obedient. Even if employers would appreciate obedient employees, it could be hypothesized that obedience can suppress creativity and freedom in certain occupations [23]. We believe that this specific variable requires further research.

\section{Locus of control}

The other major part of the survey was the classification of LOC. It is widely accepted that the construct of LOC has become crucial to the understanding of human behaviour in work organizations. Previous research indicated that the LOC is related to excitement and empowerment in the work environment [24]. Also, a more recent study found that employees who believed they could control their reinforcements through their own behaviour experienced higher levels of job satisfaction [25]. Furthermore, a significant amount of research suggests that individuals with more persistence had more internalized locus of control [26]. Persistence was defined as individuals who were more likely to display the following behaviours: ability to stay on task without prompting; work steadily along the entire work period; and work at routine jobs without resistance. It is well known the high levels of job satisfaction lead to job productivity [27]. The finding that the majority of our sample (54.7\%) had internal or strongly internal LOC suggested that this group of employees believe that the achievements or failures in their work environment are the results of their own actions or efforts and not that the environment or the circumstances influence the outcomes.

\section{Summary}

In summary, the authors believe that this case study in Cyprus has revealed some interesting descriptive statistics regarding the value systems and LOC of individuals who have undergone aesthetic plastic surgery. This group scored highly on many of the values that could be seen as important in the work environment. In addition, a small majority of the sample has internal LOC and these employees are in a position to recognize that their actions influence the outcomes in any given work environment. All this information can be applied directly in work environments and used by experts in human resources management, organizational psychology and strategic management. Follow-up research with the addition of a control group would be useful to determine how employees who have undergone aesthetic plastic surgery differ from the general population regarding these variables. More research is required in order to investigate some contradictions in the findings.

\section{References}

1. Rokeach M. The nature of human values. New York, Free Press, 1973.

2. Schwartz SH. Are there universal aspects in the structure and contents of human values? Journal of Social Issues, 1994, 4:19-45.

3. Schwartz SH, Bilsky W. Toward a psychological structure of human values. Journal of Personality and Social Psychology, 1987, 53:550-562.

4. Schwartz SH, Bilsky W. Toward a theory of the universal content and structure of values: Extensions and cross-cultural replications. Journal of Personality and Social Psychology, 1990, 53:550-562.
5. Schwartz SH, Sagiv L. Identifying culture-specifics in the content and structure of values. Journal of Cross-Cultural Psychology, 1995, 26(1):92-116.

6. Schwartz SH, Sagie G. Value consensus and importance a cross-national study. Journal of Cross-Cultural Psychology, 2000, 31(4):465-497.

7. Rotter J. Generalized expectancies for internal versus external control of reinforcements. Psychological Monographs: General and Applied, 1966, 80(1):1-28. 
8. Clinite BJ. Understanding women's experience in the workplace as it relates to their conceptualizations of power, professionalism, and success. Dissertation Abstracts International. B, The Sciences and Engineering, 2000, 61(5-B).

9. Wang Q, Bowling NA, Eschleman K. A meta-analytic examination of work and general locus of control. Journal of Applied Psychology, 2010, 95:761-768.

10. Roddenberry A, Renk K. Locus of control and self-efficacy: potential mediators of stress, illness, and utilization of health services in college students. Child Psychiatry and Human Development, 2010, 41:353-370.

11. Williams AM. An examination of generation nexters and baby boomers value systems in a service organization. Dissertation Abstracts International. A, The Humanities and Social Sciences, 2010, 70(12-A)

12. Moss TP, Harris D. Psychological change after aesthetic plastic surgery: a prospective controlled outcome study. Psychology Health and Medicine, 2009, 14:567-572.

13. Pavan C, Vindigni V, Semenzin M. Personality, temperament and clinical scales in an Italian plastic surgery setting: what about body dysmorphic disorder? International Journal of Psychiatry in Clinical Practice, 2006, 10:91-96.

14. Pruzinski T et al. Psychological aspects of reconstructive and cosmetic plastic surgery: clinical, empirical, and ethical perspectives. Philadelphia, Pennsylvania, Lippincott Williams and Wilkins, 2006:3-11.

15. Foustanos A, Pantazi L, Zavrides H. Representations in plastic surgery: the impact of self-image and self-confidence in the work environment. Aesthetic Plastic Surgery, 2007, 31:435-442.

16. Foustanos A, Pantazi L, Zavrides H. Representations in plastic surgery: the impact of self-image and self-confidence in work environment. Aesthetic Plastic Surgery, 2007, 31:435-442.

17. $\mathrm{Xu} \mathrm{X}$ et al. Motivation and social contexts: A cross-national pilot study of achievement, power, and affiliation motives. International Journal of Psychology, 2012, 47(2):111-117.
18. Zhang X, Bartol K. Linking empowering leadership and employee creativity: the influence of psychological empowerment, intrinsic motivation, and creative progress engagement. Academy of Management Journal, 2010, 53(1):107-128.

19. Morris JA, Urbanski J, Hunt J. Unto others: illustrating the human capacity for cooperation. Journal of Management Education, 2011, 35(2):260-281.

20. Underwood J, Harrison A. Perfectionist at 20-work-life issues at 40 ? Personal value systems and future implications. Interbeing, 2009, 3(1):31-36.

21. Prietula M, Carley KM. Exploring the effects of agent trust and benevolence in a simulated organizational task. Applied Artificial Intelligence, 1999, 13(3):321-338.

22. Lindridge AM, Congying W. Saving "face" in China: modernization, parental pressure, and plastic surgery. Journal of Consumer Behaviour; 2008, 7(6):496-508.

23. Turnipseed DL. Are good soldiers good? Exploring the link between organization citizenship behavior and personal ethics. Journal of Business Research, 2002, 55(1):11-15.

24. Erbin-Rosemann MA, Simms L. Work locus of control: the intrinsic factor behind empowerment and work excitement. Nursing Economics, 1997, 15(4):183-190.

25. Tillman JT. Work locus of control and the multidimensionality of lob satisfaction. Journal of Organizational Culture. Communications and Conflict, 2010, 14(2).

26. Thomas WH, Sorensen KL, Eby LT. Locus of control at work: a meta-analysis. Journal of Organizational Behavior, 2006, 27:1057-1087.

27. Bockerman $\mathrm{P}$, Ilmakunnas $\mathrm{P}$. The job satisfaction-productivity nexus: A study using matched survey and registered data. Helsinki, Centre of Economic Research, 2010 (Discussion Paper No. 297). 